\title{
COMPARISON OF ENERGY EFFICIENCY DETERMINATION METHODS FOR THE INDUCTION MOTORS
}

\author{
Bator Tsybikov ${ }^{1}$, Evgeniy Beyerleyn ${ }^{1, *}$, and Polina Tyuteva ${ }^{1}$ \\ ${ }^{1}$ Tomsk Polytechnic University, 634050, Tomsk, Russia
}

\begin{abstract}
In the paper the effects on the induction motor efficiency determination due to the introduction of the EU, USA, Canada, Japan and Russian Standards have been analyzed and discussed. Industrial induction motor has been tested and a comparison between the efficiencies determined by various National Standards has been presented. In addition, the motor efficiencies have been compared with the efficiency classes defined by the EU Standardization.
\end{abstract}

\section{Introduction}

Currently, induction motors are played the most important part in the alternating electric drivers due to their robust construction, easy operation, self-starting and rather high reliability in comparison with direct current or synchronous motors that have many considerable drawbacks. Mostly such machines present small or average power motors with traction mode, induction generators are used quite rarely. As induction motors represent one of the most important power equipment, so the power consumption of them accounts for a large proportion $[1,2]$. Induction motor efficiency states how much electrical power is converted to useful work (mechanical power); also what part of the electrical power is lost. Factors which influence efficiency of the induction motors used in industrial applications vary and these must be taken into account to minimize energy losses. The ways of power consumption reduction are discussed in considerable details in variety of articles. But not only the question of minimization of losses in induction motors should be under close attention, but also the approaches of accurate efficiency determination of the induction machines [3]. The purpose of our article is to provide comparison between methods of efficiency determination for the induction motors according to various National Standards.

\section{Losses and efficiency in induction motors}

According to the standards there are two major ways of efficiency determination of the induction motors are implemented: direct and indirect. The usage of the direct method means that the motor efficiency is determined from the direct measurements of the input electrical power $P_{\text {in }}$ and output mechanical power $P_{\text {out }}$. The direct method is generally

\footnotetext{
* Corresponding author: beierleinev@tpu.ru
} 
thought as less accurate as it applies the direct measurement of input and output values of power:

$$
\eta=\frac{P_{\text {out }}}{P_{\text {in }}} .
$$

In the indirect method, the input power and output power may also be measured and used to determine the constituent components of the losses in the motor this process is known as segregation or summation of the losses. The efficiency is determined from the total losses, $P_{\text {loss }}$, by equation:

$$
\eta=\frac{P_{\text {in }}-P_{\text {oss }}}{P_{\text {out }}} .
$$

The efficiency determination methods that are based on loss segregation are known to be more accurate. There are five categories of losses in the motor: $P_{\text {core }}$ is the core losses, $P_{f w}$ is the friction and windage losses, $P_{\text {stator }}$ is the stator copper losses, $P_{\text {rotor }}$ is the rotor copper losses, and $P_{\text {stray }}$ is the stray load losses, the distribution of the losses is given on Fig. 1 ( $P_{a g}-$ air-gap power, $P_{m}$-mechanical power).

The core losses and the friction and windage losses are known as constant losses because they are considered independent of the value of the load. Core losses represent the amount of energy required to the core magnetization process. The friction and windage losses appear due to bearing friction and air resistance, which is primarily caused by the cooling fan.

The other losses are considered load dependent and therefore variable with load. The stator and the rotor copper losses occur due to current flow through the resistance of the stator and the rotor windings. The fixed losses could be determined from no-load tests at variable voltage and the conventional load losses are determined from load tests as described in various literature.

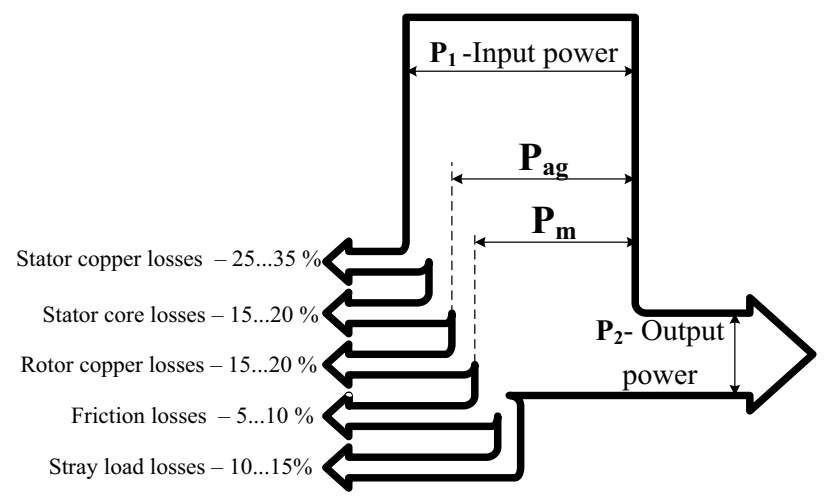

Fig. 1. Distribution of the losses in the induction motors.

Both methods have direct connection with all losses in the motor. Engineers are trying to minimize the percentage of losses, cause each percent is very important for electrical energy industry. There are several effects that could influence and minimize the losses that occur in the induction motors:

1. Stator core losses - could be reduced by using of improved permeability steel, lengthening core, using thinner laminations in the core.

2. Stator and rotor copper losses - could be reduced by increasing the volume of copper wire in the stator, through improved stator slot designs, and by using thinner insulation. 
In a case of squirrel cage rotor the copper losses could be reduced by increasing the size of rotor conductive bars and end rings to reduce resistance.

3. Friction and windage losses - using the lower friction bearings, improved fan design and air flow could effect on the losses reduction.

4. Stray losses - as this type of the losses appear mostly due to leakage fluxes induced by load currents thus various design and manufacturing details may influence on them.

Energy losses are the determining factor in motor efficiency. The losses, as it shown earlier, could be divided into five main classes, Fig.1. In the next parts of this paper we will give an overview of various National Standards for efficiency determination and discuss the main differences between them.

\section{National standards for induction motors testing}

Since the induction motor consumes about $90 \%$ of all the electrical energy used by all motors combined, its efficiency reporting on the nameplate has become the industry standard. However, various international standards for testing and reporting the induction motor efficiency on the nameplate can be significantly different. National and International energy efficiency test standards have been developed to reduce the errors when motor efficiency is measured and make the procedure standardized. There are exist a number of international standards that are used to determined real efficiency according to experimental data. The major and the most important Standards for poly-phase induction motors efficiency measurement are [3]: IEEE Std. 112 - USA Standard; IEC 60034-2-1 - EU Standard; CSA C390 - Canadian Standard; JEC 37 - Japanese Standard; IEC 60034-2 Russian Standard; GOST 25941-83 - Russian Standard [4-9].

Most of these National Standards have more than one method for the efficiency determination, for example the IEEE Std. 112 has several methods identified as Methods A, $\mathrm{B}, \mathrm{B} 1, \mathrm{C}, \mathrm{E}, \mathrm{E} 1 \mathrm{~F}, \mathrm{~F} 1, \mathrm{C} / \mathrm{F}, \mathrm{E} / \mathrm{F}, \mathrm{E} 1 / \mathrm{F} 1$. The IEEE 112 standard, method B, is commonly used for induction motor efficiency determination. The method is based on the summation of losses of the motor into conventional and additional (stray load) losses. The CSA 390 Standard uses an identical procedure to the IEEE Std. 112 method B for the stray load losses while the JEC 37 Standard ignores those losses [7]. The European standard for measuring motor efficiency, IEC 60034-2-1 has for a long time arbitrarily assigned $0.5 \%$ input power as stray load loss, the same stray load losses determination we have in IEC 60034-2-1 and GOST 25941-83. The major differences between these standards is in the treatment of stray load losses, see Table 1 below.

Table 1. The comparison between major test Standards

\begin{tabular}{|l|l|l|}
\hline \multicolumn{1}{|c|}{ Standard } & \multicolumn{1}{|c|}{ Stray losses } & \multicolumn{1}{c|}{$\begin{array}{c}\text { Temperature } \\
\text { correction }\end{array}$} \\
\hline IEEE Std. 112 & Loss segregation method & Yes \\
\hline IEC 60034-2-1 & Loss segregation method & Yes \\
\hline CSA C390 & Loss segregation method & Yes \\
\hline JEC 37 & Ignores SLL & Yes \\
\hline GOST 25941-83 & Assigns 0.5\% of rated power of the motor & No \\
\hline
\end{tabular}

The loss segregation method (used in IEEE, IEC, GOST and CSA) determines efficiency through the direct method or separation of loss method. This method requires an open-circuit and load test, under open-circuit the core and windage and friction loss are segregated and the stator and rotor copper losses recieved under the load test. The stray load loss is determined by subtracting all the major losses from the total measured loss. As stray load losses are the smallest one, they are sensitive to errors in measurement. The IEEE 
Std. 112 requires a correlation factor of 0.90 while the Canadian standard CSA C390 requires factor of 0.95. The GOST 25941-83 method allocates stray load losses to be $0.5 \%$ of rated load and the Japanese one JEC 37 ignores stray load losses completely.

\section{Efficiency levels}

These standards also play an important role in induction motor classification according to efficiency levels. In the European Union (CEMEP) and the U.S (EPAC) laws have been set to define the efficiency class of induction motors [2]. Table 2 shows the requirement limits for the efficiency according to the CEMEP classification. These limits are determined through testing according to a particular standard (IEC in this case). Previously in Europe, low voltage three-phase motors have been graded and marketed in three efficiency classes EFF3, EFF2 and EFF1 - based on a voluntary agreement between motor manufacturers and the European Commission. Unfortunately, other countries have also developed their own national systems, which are very different from the European system. That was the reason for the European motor manufacturers in CEMEP, to develop an energy efficiency standard for the International Electrotechnical Commission (IEC). The new international standard defines efficiency classes IE1, IE2 and IE3 for three-phase motors. The efficiency classes for induction motors according to the new classification is shown in Table 2.

Table 2. Efficiency classes of CEMEP classification for 4-pole, $50 \mathrm{~Hz}$ induction motor.

\begin{tabular}{|c|c|c|c|}
\hline Rated power, $\mathrm{kW}$ & $\begin{array}{c}\text { IE1 (EFF2) } \\
\text { Standard efficiency }\end{array}$ & $\begin{array}{c}\text { IE2 (EFF1) } \\
\text { High efficiency }\end{array}$ & $\begin{array}{c}\text { IE3 } \\
\text { Premium efficiency }\end{array}$ \\
\hline 0.75 & 72.1 & 79.6 & 82.5 \\
\hline 1.1 & 75 & 81.4 & 84.1 \\
\hline 1.5 & 77.2 & 82.8 & 85.3 \\
\hline 2.2 & 79.7 & 84.3 & 86.7 \\
\hline
\end{tabular}

The differences in treatment of stray losses have been seen to produce different efficiencies on the same tested motor. A $1.1 \mathrm{~kW}$ induction motor was tested according to various National Standards. Due to the similarity in testing standards, only the IEEE Std. 112, IEC 60034-2-1 - direct method, JEC 37 and GOST 25941-83 loss segregation method were used.

\section{Experimental study}

For experimental studies of the induction motor energy performance it is required to select the type of installation unit. Selecting of circuit for testing of electrical motors is determined by the parameters of the equipment installed on testing platform 2 that can be characterized by quantitative and qualitative parameters [10]. In general, the installation unit for experimental data determination includes: tested motor, loading machine and measuring equipment. In the function of measuring equipment we use current and voltage sensors that are connected to the phases of stator winding. CIRCUTOR AR.5 (portable power analyzer) is used as processing system for current and voltage sensors data processing.

The following experiments were provided for determining the efficiency of the tested induction motor: the measurement of phase resistance of the stator winding; idle running mode performance; load mode performance. Load mode performance is produced by the different connected to the motor shaft in the range from not less than $10 \%$ in excess of the rated power to the idle running mode, the load changing is carried out by lowering the load. 
Before the experiment performance the pilot running should be done to warm induction motor in the case stator and rotor windings temperature should achieve the steady value.

The following values are measured in the course of the experiments: voltages in each phase and the average value; currents in each phase and the average value; main supply frequency; power factor in each phase; rotor speed. The measurement results are undergoing the following treatment: the actual line voltage applied to the stator windings were takenc as the arithmetic average of the measured values, the actual line current were taken the arithmetic average of the measured values, the rotor speed was measured by direct current tachogenerator mounted on the load of the generator shaft.

The experimental test results are shows the difference in efficiency values using different standards, Fig. 2.

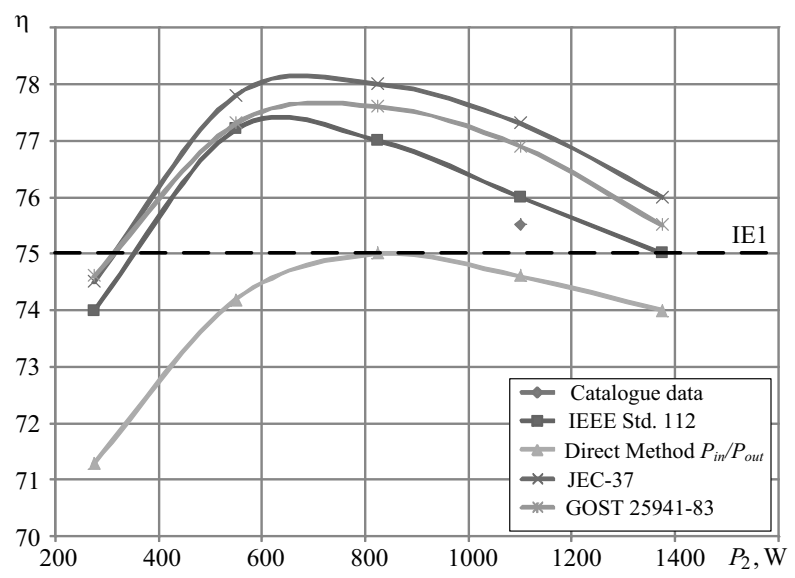

Fig. 2. Efficiency of $1.1 \mathrm{~kW}$ induction motor according various standards.

Fig. 2 compares the efficiency of a $1.1 \mathrm{~kW}$ induction motor derived from four international standards, namely, the IEEE Std. 112, IEC 60034-2-1 (direct method), JEC 37 and the GOST 25941-83. The direct method IEC 60034-2-1 and IEEE Std. 112 result in the lowest efficiency. The difference comes from the different treatments of the stray load losses. The IEEE Std. 112 derives it indirectly from tests, and the GOST 25941-83 assumes to be fixed $0.5 \%$ of the rated power, whereas the JEC-37 ignores it altogether, resulting in the highest efficiency. The difference between founded levels of efficiency results in that the classification according CEMEP could have this motor as IE1 Standard efficiency or in a case of direct method the value of efficiency is lower than desired level and the difference would be more significant in the case of higher rated power motors. The main point is that a standard efficiency motor made in the one country cannot be compared with a motor made in another one for energy-saving considerations.

Not only the assumed National Standardization, but also some other various aspects could have impact on the efficiency level:

1. Quality of power supply, according to the standards the power supply should not have the voltage unbalance exceed $0.5 \%$ and frequency $0.1 \%$ of rated values. The fluctuations of voltage magnitude and frequency, any unbalance has an impact on the accuracy of the experimental data.

2. Equipment of test platform, instrumentation plays a large role in determining efficiency with a high accuracy, as well as the process of measurement equipment calibration. Calibration of measurement instruments resulted in the confidence in the experimental results. 


\section{Conclusion}

This paper highlighted the main factors that influence induction motors efficiency in industry. The value of induction motor efficiency can be affected by various aspects one of them is National Standardization. The paper considers the influence of various standards on the value of induction motor efficiency and the efficiency level in accordance with CEMEP is evaluated. As efficiency level determined in accordance with National standards depends on the stray load losses accuracy determination in the future it is planned to work on the development of the experimental procedure for stray load losses determination which takes into the account the impact from power supply characteristics and the features of test equipment.

\section{References}

1. H. Mzungu, P. Barendse, A. Khan, M. Manyage, Industrial and Commercial Use of Energy, 1 (2008)

2. E. Agamloh, Electric Machines and Drives Conference, 36 (2009)

3. O. Dobzhanskyi, R. Gouws, Industrial and Commercial Use of Energy (2014)

4. IEC 60034-2-1, Rotating Electric Machines Part 2-1: Standard methods for determining losses and efficiency, 53 (2007)

5. IEEE Std. 112: Test Procedure for Polyphase Induction Motors and Generators, IEEE, 79 (2004)

6. CSA C390: Energy Efficiency Test Methods for Three-Phase Induction Motors, Canadian Standards Association, 79 (2004)

7. JEC 37: Induction Machine, Standard of Japanese Electrotechnical Committee, 44 (1979)

8. GOST 7217-87. Rotating electrical machines. Asynchronous motors. Test methods, 42 (2003)

9. GOST 25941-83. Rotating electrical machines. Methods for determining losses and efficiency,31 (2003)

10. E. V. Beyerleyn, P. V. Tyuteva, Micro/Nanotechnologies and Electron Devices (2014) 